\title{
UM CONTRAPONTO ENTRE OS PERSONAGENS DOS CONGRESSOS BRASILEIROS DE ENFERMAGEM E DA REVISTA BRASILEIRA DE ENFERMAGEM NO PERÍODO DE 1977 A 1987
}

\author{
A COUNTERPOINT AMONG PERSONALITIES AND ISSUES OF THE BRAZILIAN NURSING \\ SCENARIO FROM 1977 TO 1987
}

\section{UN CONTRAPUNTEO ENTRE LOS PERSONAJES DE LOS CONGRESOS BRASILEROS DE ENFERMERÍA Y DE LAREVISTA BRASILERA DE ENFERMERÍA EN EL PERIODO DE 1977 AL 1987}

\author{
Miriam Susskind Borenstein ${ }^{1}$ \\ Maria Itayra Coelho de Souza Padillha² \\ Alcione Leite da Silva ${ }^{3}$
}

RESUMO:Tem como objetivo realizar o contraponto entre algumas idéias dos personagens centrais dos Congressos Brasileiros de Enfermagem e dos editoriais das Revistas Brasileiras de Enfermagem no periodo de (1977-1987). Analisamos nove anais e 24 editoriais. Os resultados mostram que o conteúdo das temáticas respondiam a política da ABEn-Central. Os personagens procuravam corresponder as solicitações destas lideranças evidenciando a influência da Escola Ana Nery e da Escola de Enfermagem da USP nos discursos. É marcante a participação de docentes de Escolas Enfermagem Federais. Os homens Enfermeiros marcaram pouco na época, exceto por aqueles que participaram do movimento PARTICIPAÇÃO. Encontramos apenas um editorial redigido por Enfermeiro. Observamos mudanças nos rumos da ABEn - Central, posterior a 1984 decorrente do movimento PARTICIPAÇÃO, influenciando os temas nos congressos, os debatedores e os editoriais da REBEn.

PALAVRAS-CHAVE: história da enfermagem, congressos brasileiros de enfermagem, revista brasileira de enfermagem

ABSTRACT: This is a qualitative study, using an exploratory approach, which has as its main aim to analyze and counterpoint central issues and personalities of the Brazilian Nursing Conferences and the editorials of the Brazilian Nursing Journal, from 1977 to 1987 . It was analyzed 09 annuals and 24 editorials. The results show that the contents were aligned with the policy of the central ABEn. The leadership of Ana Nery School and USP Nursing School is evident in this period. Male nurses had no expressive participation in the nursing conferences, except those who were members of the PARTICIPAÇÃO movement. We found only one editorial written by a male nurse. We observed changes in the central ABEn policy after 1984 provoked by the PARTICIPAÇÃO movement and, influencing the change of subjects at the conferences, and the editorials of the REBEn.

KEYWORDS: nursing history, Brazilian Nursing Conferences, Brazilian Nursing Journal

RESUMEN:Tiene como objetivo realizar el contrapunteo entre algunas ideas de personajes centrales de los Congresos Brasileros de Enfermería y de las editoriales de las Revistas Brasileras de Enfermeria en el periodo de (1977 al 1987). Fueron analisados nueve anuales y 24 editoriales. Los resultados demuestran que el contenido de las temáticas respondian a la política de la ABEn-Central. Los personajes intentaban corresponder a las solicitudes de estas lideranzas y es evidente la influencia de la Escuela Ana Nery, y de la Escuela de Enfemería de la USP. Es resultante la participación de docentes de Escuelas de Enfermeria de Universidades Federales. Los Enfermeros destacaron poco, excepto aquellos en el movimiento PARTICIPACIÓN. Encontramos tan solo un editorial dirigido por un Enfermero. Observamos un cambio en los rumbos de la ABEn-Central, posterior al año 1984 decurrente del movimiento PARTICIPACIÓN, influenciando los temas en los congresos, debatidores i los editoriales.

PALABRAS CLAVE: historia de enfermeria, congresos de enfermeria, Revista Brasilera de Enfermería

Recebido em 31/08/2002

Aprovado em 27/09/2002

\footnotetext{
${ }^{1}$ Doutora em Enfermagem. Prof. Adjunta do Depto. de Enfermagem da UFSC. Pesquisadora do CNPq. Coordenadora do GEHCE (Grupo de Estudos da História do Conhecimento da Enfermagem)

${ }^{2}$ Doutora em Enfermagem da UFSC. Prof. Adjunta do Depto. de Enfermagem da UFSC. Membro do GEHCE. Pesquisadora do CNPq.

${ }^{3}$ Doutora em Filosofia de Enfermagem. Prof. Titular do Depto. de Enfermagem da UFSC. Pesquisadora do CNPq.
} 


\section{SITUANDO O TRABALHO}

O presente estudo faz parte do Projeto intitulado, em sua primeira versão: "Caminhos da Construção do Conhecimento da Enfermagem Brasileira, de 1965 a 1995", desenvolvido pelo GEHCE (Grupo de Estudos da História do Conhecimento da Enfermagem). Este grupo, constituido por docentes de Enfermagem e de História, discentes do Doutorado em Filosofia da Enfermagem e de alunos de graduação em Enfermagem é vinculado ao Departamento de Enfermagem da Universidade Federal de Santa Catarina. Vem trabalhando desde março de 1995, quando o projeto foi aprovado pelo $\mathrm{CNPq}$ (Conselho Nacional de Desenvolvimento Científico e Tecnológico), passando a ser financiado. Inicialmente, o grupo manifestou interesse em trabalhar sobre a trajetória do conhecimento produzido pela enfermagem no país, durante os últimos trinta anos, entretanto, face ao exíguo tempo e a necessidade de um maior aprofundamento no estudo, nesta primeira etapa, passou a ser focalizado prioritariamente o conteúdo referente as publicações dos "Anais dos Congressos Brasileiros de Enfermagem" cobrindo os seus dez primeiros anos de publicação (1977-1987) para, então, posteriormente, prosseguir o estudo. Ao longo das leituras consideramos importante incluir os editoriais da Revista Brasileira de Enfermagem no sentido de perceber o cenário pelo qual passava a Enfermagem brasileira da época, e realizar um contraponto entre estes dois segmentos tão importantes na constituição da Associação Brasileira de Enfermagem.

Este contraponto permitiu compreender o contexto, o clima, as cores sociais, e os sujeitos centrais que retratam as cenas historicamente transcorridas, possibilitando a abstração acerca da realidade da época, sendo que a sintese traçada procura refletir uma parte da trajetória do conhecimento percorrido pela Enfermagem na década estudada.

\section{CONTEXTUALIZANDO OS CONGRESSOS BRASILEIROS DE ENFERMAGEM}

A Enfermagem desde sua criação como profissão no cenário brasileiro procurou avançar continuamente, criando a Associação Brasileira de Enfermagem em 1926, a Revista Brasileira de Enfermagem em 1932, desencadeando o surgimento de inúmeras leis, criação de conselhos, sindicatos, cursos de pós-graduação strictu sensu e latu sensu, entre outros. O Congresso Brasileiro de Enfermagem tornou-se uma atividade regular da ABEn, a partir de 1947, sendo realizado anualmente em uma capital do país. Somente não ocorreu no ano de 1953, quando a ABEn hospedou o X Congresso Quadrienal do ICN, em Petrópolis e, em 1961, quando ocorreu no Rio de Janeiro o Congresso do CICIAMS 4 .

O CBEn é o mais competente instrumento criado pela ABEn para passar sua mensagem aos sócios, ainda que não seja o único. Mas neste é possivel perceber a presença do pensamento da diretoria que está no comando. Esta delega a organização do CBEn à seção que vai sediá-lo. Parece claro que a seção terá autonomia com relação ao temário, mas na fase de construção as comissões têm de aceitar sugestões da Diretoria nacional, inclusive indicação de palestrantes. Sendo que a programação do evento se aprova em CONABEn (MANCIA, 2002, p. 43).

Nos início dos anos 80 , a ABEn, passa a engajarse politicamente, no movimento de luta pelos direitos dos trabalhadores. Os enfermeiros passam a desenvolver uma visão mais critica acerca do sistema de saúde vigente e da necessidade de democratização da mesma, não apenas no sentido de ampliação dos serviços mas, sobretudo, da sua qualidade em todos os niveis de complexidade (PEREIRA, 1995).

Dentro da Associação Brasileira de Enfermagem (ABEn), essa tomada de consciência já começava a ser notada durante a realização do XXXI Congresso Brasileiro de Enfermagem, ocorrido em Fortaleza - Ceará em 1979, quando a professora da Escola Ana Nery, enfermeira leda Barreira e Castro (então presidente da ABEn Central), manifestava em seu discurso, a necessidade da Enfermagem sair de sua passividade e tolerância, para uma inconformação, buscando novas alternativas de solução para os seus problemas. Este tipo de discurso, clamava para que os enfermeiros se comprometessem, e provocassem as desejadas mudanças na enfermagem e até quem sabe, junto com outros profissionais, provocassem mudanças no Sistema de saúde.

Mesmo correndo o risco de simplificarmos demasiadamente as mudanças que ocorreram na ABEn, houve três alterações básicas, traduzidas através da metáfora dita pela presidente em seu discurso de abertura do XXXI CBEn ..."novos ventos sopram na ABEn...".

A primeira alteração vinha se dando no âmbito da formação de um novo contingente de profissionais enfermeiros, docentes e assistenciais. Provenientes de novos cursos de Graduação de Enfermagem, de dezesseis Universidades Federais do País, estes novos enfermeiros tinham tido uma nova proposta de currículo - prática-teorizada que, com certeza, redundaria numa nova prática e num comprometimento político. A disposição e a participação política desses novos enfermeiros era mais de enfrentamento do que de aguardar determinações.

A segunda alteração estava na criação de outras entidades de Enfermagem e principalmente na aproximação com outras categorias da enfermagem, como a do auxiliar e a do técnico de enfermagem, assim como do atendente. Este último, segundo a legislação vigente, deveria ser capacitado pelo enfermeiro dentro das instituições de saúde, como auxiliar de enfermagem, num prazo de dez anos (197686) (PEREIRA, 1995).

A formação de entidades sindicais de Enfermeiros (Rio Grande do Sul - 1976, e Rio de Janeiro - 1977), bem como a criação do Conselho Federal (1975) e Regionais, também concorreram para as alterações no processo de viver politicamente a profissão da enfermagem e a participação política na sociedade brasileira.

Além das entidades de enfermagem, os cursos de Pós-Graduação surgidos na década de 70 , suscitaram uma intensificação na produção científica, surgindo a criação do

${ }^{4}$ Comitê Internacional Católico de Enfermeiras e Assistentes Médicos-Sociais. 
CEPEn (Centro de Estudos e Pesquisa em Enfermagem) e a organização de eventos científicos de expressão, como os SENPE (Seminário Nacional de Pesquisa em Enfermagem), que passou a ocorrer bianualmente. Além desses, uma sistemática de produção de projetos de importância, nos vários niveis: local, regional e nacional, que teve como conseqüência, uma maior clareza da situação da enfermagem. A partir desse momento, operou-se transformações no modo de perceber o ensino e a pesquisa, e consequentemente a assistência à saúde da população.

A história do movimento PARTICIPAÇÃO nasceu e confundiu-se com a história da redemocratização do País. A retomada do governo civil fez perceber nas discussões, tanto as internas da profissão, como naquelas relacionadas aos novos projetos de saúde, uma expressão do pessoal de enfermagem, especialmente das enfermeiras. Havia uma necessidade de manifestar-se não somente, com relação à profissão, mas também nas questões relativas às atividades político-partidárias de reorganização social do pais. Era a vez de retomar o voto e a voz era para dizer "Diretas Já", não só para eleições presidenciais, mas para todas as decisões coletivas importantes, principalmente, as especificas de enfermagem.

Esse movimento provocou uma caminhada acelerada de mudanças na ordem até então estabelecida, tradicionalmente aceitas pela $A B E n$, nos Congressos, nas Assembléias de Delegados e na condução dos rumos da REBEn. Dava-se agora, primazia á criação coletiva, que só, então, se concretizaria, pela participação de todas as categorias de Enfermagem em projeto que buscasse uma unidade, dentro da diversidade.

A terceira alteração, diz respeito ao reagrupamento livre dos associados, a partir do surgimento do Movimento PARTICIPAÇÃO (os comprometidos com o movimento, os envolvidos, porém não comprometidos e os que repudiavam o movimento).

Do grupo constituido pelos comprometidos e pelos envolvidos mas não comprometidos, surgiu um novo grupo que parecia reunir as lideranças mais jovens da velha $A B E n$. Este teve como conseqüência a criação de uma certa independência no trato das situações e na tomada de decisões. 0 repúdio ao movimento, em geral, provinha dos membros que haviam durante um longo período de tempo, exercido cargos de liderança, antes da deflagração do movimento.

Apesar dos ânimos exaltados dentro da ABEn, os seus membros se mantinham firmes nas suas opiniões a cerca da luta pela qualidade de saúde e do cuidado de enfermagem prestado. Assim, os embates em prol da Reforma Sanitária e as caminhadas prévias para chegada ao SUS compreendia, nos anos 80 , uma força de unidade em torno da que se consubstanciava na expressão todo o direito a saúde corresponde igual direito a qualidade do cuidado de enfermagem.

A partir de 1979, com o XXXI Congresso Brasileiro de Enfermagem ocorrido no Ceará, parece ter havido um rompimento entre uma enfermagem que costumava discutir as questões políticas em sintonia com as instituições governamentais e autoridades, para uma que pretendeu se atrelar ao processo político- partidário, mais envolvida com as questões político-partidárias, com a enfermagem atrelada à situação pela qual passava o país, e com preocupações com o trabalhador da enfermagem (nos seus diversos niveis). Essas mudanças se associam com a formação da chapa Participação, que descreve uma mudança na trajetória da enfermagem a partir do início da década de 80 . Estas tendências dai derivadas, geraram novos conhecimentos a partir de várias vertentes, por vezes associadas: da prática assistencial associada à tecnologia e à teoria; da investigação científica tendo por base linhas de pesquisa, e finalmente o conhecimento que procede das experiências, a partir do ensino da área da enfermagem.

\section{CONTEXTUALIZANDO A REVISTA BRASILEIRA DE ENFERMAGEM NO PERÍODO}

Em 20 de maio de 1932 ocorreu o lançamento do número um de Annaes de Enfermagem, a primeira revista de enfermagem brasileira, e que em 1954 seria denominada Revista Brasileira de Enfermagem (CARVALHO, 1976). No primeiro editorial da nova revista, Raquel Haddock Lobo, primeira editora do periódico, o apresenta como o arauto da profissão, uma vez que é o primeiro entre as enfermeiras (LOBO, 1932).

Mancia, (2002) em reflexão teórica sobre a REBEn afirma que em seus primeiros vinte anos de existência, esta publicou artigos que na sua maioria provinham da Escola Anna Nery e da Escola de Enfermagem da USP/SP, além de publicar muitos textos de profissionais médicos. Entre os anos de 1947 e 1976 dedica um ou mais fascículos por ano, da revista ao Congresso Brasileiro de Enfermagem (CBEn) divulgando conferências, programação e recomendações, prática esta ao nosso ver decorrente da baixa produção científica da enfermagem na época.

Vale ressaltar que o primeiro curso de Mestrado no Brasil foi criado em 1972, na Escola de Enfermagem Anna Nery, tendo ocorrido um incremento das produções científicas, com vinculação inicial relacionada aos programas de pósgraduação, e também os Anais dos CBEns. Este último passou a ter publicação própria a partir de 1977.

Nos anos 80, a diretoria da ABEn encontra grandes dificuldades no financiamento da revista, o que prejudica a regularidade da mesma. Receber a revista se constituía em direito do sócio, conforme determinação do estatuto que havia incluído este artigo em 1962, porém a impressão do periódico era muito cara. Eram necessários aproximadamente 10.000 exemplares para distribuir a REBEn para todos os sócios, sendo também distribuídos para assinantes institucionais, não sócios, permutas, assinaturas internacionais, o que facilmente chegaria a 15.000 revistas.

As dificuldades encontradas levaram a primeira diretoria do Movimento Participação, através decisão de Assembléia Nacional de Delegados de desvincular o recebimento do periódico do pagamento da anuidade da ABEn. Atitude recebida inicialmente com muita crítica por parte dos enfermeiros interessados na REBEn, passou, a partir de 1990, a ser distribuída somente pelo sistema de assinaturas (MANCIA, 2002).

Os cinquenta anos da revista completados em 1982, não são referenciados nos editoriais daquele ano. Haydée Guanais Dourado, responsável pela maioria dos editoriais 
da década analisada, escreve sobre tema "fortalecendo a profissão", no qual faz uma reflexão sobre a evolução da assistência de enfermagem, enquanto profissão, afirmando:

“Ganhar, perder ou viver!" está na hora de termos bom senso e de cerrarmos fileira, unidos, para que os serviços de enfermagem deste pais se organizem e tenham um desempenho à altura do que já sabemos ser exequivel. Estamos recusando continuar com um nivel indesejável de serviços de enfermagem. Unidos, sabendo o que queremos, podemos ganhar essa batalha de vida (DOURADO, 1982, p. 2).

\section{A METODOLOGIA DO ESTUDO}

A fim de dar uma visão mais clara ao leitor de como foi realizado o trabalho, sentimos a necessidade de descrever a metodologia empregada. Inicialmente buscou-se resgatar todos os Anais dos Congressos Brasileiros de Enfermagem. Não analisamos os anais do XXXVIII Congresso Brasileiro de Enfermagem, realizado no Rio de Janeiro, em 1986, em função do mesmo não ter sido editado. Com exceção desse e de posse dos demais, as autoras levantaram os seguintes dados: nome de cada um dos personagens que participaram de cada uma das sessões, a titulação, a procedência e o título do trabalho apresentado. As autoras tiveram algumas dificuldades, pois nem todos os trabalhos consultados tinham claramente a procedência e a titulação completa do autor, o que em muitos momentos deixou dúvidas, entretanto as autoras fizeram cruzamento com outras fontes, a fim de clarificar algumas informações, tabulando finalmente os dados.

Com relação a Revista Brasileira de Enfermagem, optamos por analisar as temáticas e as autorias apenas dos editoriais, porque entendemos que estes contêm as idéias em evidência na Associação Brasileira de Enfermagem e dos condutores dos rumos da revista. Assim, analisamos 24 , dos 37 editoriais, o que corresponde a $63 \%$ do total.

A análise e discussão dos dados buscou estabelecer relações entre o conteúdo dos discursos dos autores centrais, no seu contexto geo - sócio - político e cultural. Após a análise relacional entre os personagens que conduziam a enfermagem brasileira nos congressos brasileiros de enfermagem e nos editoriais das revistas brasileiras de enfermagem, apresentamos a seguir os principais resultados.

\section{OS PERSONAGENS DOS CONGRESSOS BRASILEIROS DE ENFERMAGEM}

A partir do levantamento realizado nos nove Congressos Brasileiros de Enfermagem: Belém (1978); Fortaleza (1979); Brasília (1980); Manaus (1981); Porto Alegre (1982); São Paulo (1983); Belo Horizonte (1984); Recife (1985) e Salvador (1987), verificou-se que foram realizadas aproximadamente cento e setenta (170) mesas de temas oficiais, com a participação de duzentos e sessenta (260) palestrantes, sendo que desse total, somente vinte cinco (25) dosparticipantes foi constituído por homens, ou seja menos de dez por cento.

Verificamos que na maioria dos congressos, a média de mesas de temas oficiais girava em torno de doze a dezessete, e a média dos debatedores de doze a trinta.
Entretanto o XXXVII Congresso Brasileiro de Enfermagem, realizado em Recife, em 1985, se sobressaiu com a realização de sessenta e quatro (64) mesas, que se deram provavelmente de forma simultanea e que teve a preocupação de apresentar a situação real da Prática da Enfermagem, nas suas diversas especialidades, em todas as regiões do País. Este congresso contou ainda com a presença de cento e quinze debatedores, nas suas respectivas mesas. Caracterizou-se por ter sido um congresso de grande expectativa face a uma nova Diretoria da ABEn. À época, a $A B E n$ passava por uma intensa crise, em que as velhas lideranças procuraram viabilizar a posse da nova Diretoria da ABEn Central e, quem estava na Presidência, a professora Maria Ivete Ribeiro de Oliveira, docente da Escola de Enfermagem da Universidade Federal da Bahia.

Ao se analisar quem eram os debatedores, verificase que mais de noventa por cento eram constituídas por mulheres, provavelmente em função da enfermagem ser constituida na sua ampla maioria, pela presença feminina. Porisso, parece ser compreensivel a presença destas neste espaço, que se caracteriza pelo evento maior da categoria e atinge a todos os elementos da equipe de enfermagem. Observou-se ainda, que dos elementos do sexo masculino que participaram das discussões, somente dois eram enfermeiros e os demais homens eram constituídos por técnicos dos Ministérios, sindicalistas, economistas, políticos e até um empresário.

Quando se busca investigar quem eram os personagens principais (as que mais se destacaram) e de que instituições provinham, verifica-se quese caracterizavam, na sua ampla maioria, por docentes enfermeiras $(60,4 \%)$, provenientes das mais diversas Escolas de Enfermagem, de Universidades Federais do País, (poucas provinham de Universidades particulares); $26,9 \%$ eram enfermeiras que atuavam na assistência de enfermagem hospitalar e/ou na enfermagem de Saúde Pública; $6,5 \%$ eram técnicos dos diferentes Ministérios e os restantes $6,2 \%$ correspondiam a inúmeros profissionais liberais (socióloga, psicóloga, médico, economista, advogado, farmacêutico, engenheiro, entre outros). Tais personagens, provavelmente, foram convidados a participar sempre que o tema tivesse conexão da enfermagem e com estas especialidades. Além dos profissionais liberais, verificou-se, em algumas ocasiões, a presença de autoridades políticas prestigiando o evento, como por exemplo, em 1980, no Congresso realizado em Brasília, quando estiveram presentes os Ministros da Saúde e do Trabalho, e em 1985, em Recife, o Governador de Pernambuco. 0 fato dessas autoridades políticas estarem presentes ao evento, demonstra uma certa capacidade da enfermagem da época, em envolvê-las com a profissão.

Ao se relacionar de que Estados os debatedores eram provenientes, verifica-se uma maior predominância de dois Estados basicamente: São Paulo e Rio de Janeiro concorrem, seguidos em segundo lugar pelo Distrito Federal, em terceiro por Pernambuco e Bahia na mesma proporção, posteriormente por Minas Gerais e em quinto lugar, Pará. Nos demais Estados da União, a representatividade era mínima, ou quase nula. Este fato nos chama atenção, considerando que o maior número dos congressos realizados no período, foram nas regiões Nordeste (3), Norte (2) e, os demais, na regiões Centro - Oeste (1), Sudeste (2) e Sul (I). 
Pensamos que isto provavelmente decorre, do fato de que as presidentes da ABEn-Central ${ }^{5}$, no periodo estudado (1978-1987), eram respectivamente, do Rio de Janeiro (leda Barreira e Castro - 1976-1980) e São Paulo (Circe de Melo Ribeiro - 1980 - 1984), e que, provavelmente, tiveram grande influência sobre as presidentes das Comissões de Temas dos Congressos, no convite dos debatedores. Além do que, estes dois Estados estão localizados em regiões mais desenvolvidas economicamente, com maior concentração de Serviços de Saúde e de profissionais de enfermagem, especialmente de enfermeiras.

Verificamos ainda que, em muitas ocasiões, nos diferentes congressos, se repetem as mesmas debatedoras, ou seja, uma mesma debatedora pode aparecer em congressos seguidos, demostrando ser uma pessoa conhecedora e competente, mas ao mesmo tempo, inviabilizando-se o convite a outra, não proporcionando, assim, novas oportunidades. Entretanto, como a escolha das debatedoras, em geral, é feita pela Coordenadora da Comissão de Temas, em acordo com o restante da comissão e provavelmente, com as presidentes dos CBEns e da ABEn, nem sempre se consegue fugir das personalidades da enfermagem. Parece-nos, entretanto, que deveria haver uma preocupação na busca de novos debatedores, com diferentes contribuições e com um profundo embasamento técnico científico, que procurasse satisfazer necessidades dos congressistas.

Apesar da aparente ausência de uma preocupação das Coordenadores das Comissões de Temas em trazer personagens de determinadas instituições, e sim debatedoras com reconhecimento técnico-científico para trabalhar os temas propostos, percebemos terem sido as professoras da Escola Anna Nery - RJ, as mais escolhidas para apresentarem trabalhos nestes eventos, no periodo estudado. Diante deste fato, nos questionamos acerca do papel desta Escola.

Será que a predominância destas professoras nos Congressos de Enfermagem se deve ao fato desta Escola ser a mais antiga, nos moldes Nightingaleanos, ou por apresentar significativa produção científica e por isso influenciar fortemente as demais escolas? Será que o fato dos Congressos terem sido realizado mais nas regiões Norte, Nordeste e Centro-Oeste, de onde provém grande parte das enfermeiras para estudar na Escola Anna Nery, fez com que as enfermeiras destas regiões, convidassem mais as professores desta Escola, por terem sido formadas e influenciadas por elas? Ou será ainda, que a própria localização da Escola tenha contribuido?

Além do Rio de Janeiro, a capital de São Paulo também se destacou como um pólo de debatedoras nos Congressos Brasileiros, principalmente pelas professoras da Escola de Enfermagem da Universidade de São Paulo(USP), entretanto em menor proporção as da Escola Anna Nery. No entanto, a partir do Congresso Brasileiro de Enfermagem, realizado em 1981, em Manaus, quando assume Circe de Melo Ribeiro a presidência da ABEn, lentamente as professoras da USP, passam a participar mais ativamente dos eventos, fazendo uma dobradinha com as colegas cariocas. Esta situação torna-se mais saliente, quando o Congresso é realizado em 1983, em São Paulo, quando o número maior de participantes se caracterizam pelas professoras da USP. Este fato pode estar relacionado ainda, com a crescente produção científica dos alunos e docentes das Pós - Graduações emergentes, nestas duas Escolas de Enfermagem.

Podemos observar, ainda que antes do movimento Participação (até 1984), as lideranças da enfermagem eram as mesmas e permaneciam nos Estados do Rio de Janeiro e São Paulo, já comentados, com uma visão heróico-idealista da prática da enfermagem. Posteriormente vai ocorrendo uma mudança nas lideranças, com o ingresso de uma nova presidência da ABEn-Central (Maria José dos Santos Rossi - 1986-1989) com uma preocupação política e ideológica mais voltada para as questões trabalhistas, e que transparece claramente no Congresso realizado na Bahia, em 1987, com a presença de convidados apresentando temas pertinentes, como "O Processo de trabalho e a Divisão do Trabalho na Enfermagem", entre outros. Neste contexto cabe ressaltar que essa ideologia "fervilhava" nos meios acadêmicos, políticos e de imprensa, o que não poderia ser diferente com a saúde e a enfermagem.

\section{OS PERSONAGENS DA REVISTA BRASILEIRA DE ENFERMAGEM}

Os personagens que marcaram os editoriais da Revista Brasileira de Enfermagem na época estudada, acompanham as discussões que fervilhavam entre os integrantes da Associação Brasileira de Enfermagem, porém percebe-se que as temáticas abordadas nas revistas, procuravam discutir temas pontuais, como apresentaremos abaixo e nem sempre vinham ao encontro dos embates políticos pelos quais passava a profissão.

Esta afirmação se orienta pelo fato de que no periodo estudado a maioria dos editoriais foram redigidos por uma única pessoa: Haydée Guanais Dourado, talvez devido à função de redatora-chefe e de sua grande competência profissional. Interessante ressaltar que embora no periodo estudado tenham mudado três diretorias da ABEn-Central ${ }^{6}$, é só a partir de 1984, que outras personagens importantes da história da enfermagem brasileira começam a colocar suas idéias nos editoriais. Outra mudança decorrente do movimento participação é de que a partir de 1983, a REBEn institui um Conselho Científico para analisar os textos enviados para publicação ${ }^{7}$.

Os editoriais da REBEn são o veículo de divulgação

\footnotetext{
${ }^{5} \mathrm{O}$ termo ABEn Central é substituido por ABEn Nacional apenas em 1989, acreditamos que decorrente das mudanças que já vinham ocorrendo na ABEn após o movimento participação assumir a sua liderança, indicando inclusive uma descentralização do poder e maior participação das seções estaduais.

${ }^{6}$ leda de Alencar Barreira (1976-1980); Circe de Melo Ribeiro (1980-1984); Maria José Rossi (1986-1989)

7 Até 1983 a análise dos textos provavelmente se dava pelo grupo diretivo da revista composto pelo diretor responsável que era a presidente da ABEn na época; pelo editor; pelo redator-chefe; pela gerente.
} 
da ideologia dominante na entidade, como demonstram Dias, Monticelli e Nazário (1998) em análise, de quase duas décadas, dos editoriais personalizados da REBEn. Ainda que as pesquisadoras isentem a autora ${ }^{8}$ dos editoriais, atribuindo às idéias divulgadas como sendo um produto do seu tempo, como algo inexorável, inferindo neutralidade, não permitindo que se visse a editorialista como defensora daquele pensamento. As autoras finalizam o texto indicando que

Mesmo em tempos sombrios na conjuntura politica do pais, em razão da ditadura militar, em que as sombras da secreticidade ensaiaram dizer os seus textos à luz da neutralidade, isto se fez ambiguo. Os textos, de um lado, eram porta-vozes dos feitos governamentais em saúde mas, de outro lado, criavam marcadores de espaços de alento e esperança aos trabalhadores de enfermagem, nas gretas dessas mesmas legislações apresentadas editorialmente (DIAS; MONTICELLI; NAZÁRIO, 1998, p. 559)

Realizando uma análise mais especifica do conteúdo apresentado nos editoriais, podemos verificar que a Revista Brasileira de Enfermagem no periodo (1977-1987), procurava discutir variados assuntos, relativos à profissão em seus aspectos educacionais, legais, o exercicio profissional, assistenciais, pesquisa e politicas de saúde, entretanto não perdendo de vista o seu comprometimento com a sociedade brasileira, como podemos perceber através dos seus editoriais.

Apresentavam ênfase a questões como: a criação de comissão de especialistas do ensino da enfermagem, para auxiliar o MEC no traçado de suas diretrizes e ações para o ensino nacional (DOURADO, 1979a); o enfermeiro como profissional possivelmente mais adequado da equipe de saúde, para realizar a assistência primária de saúde (DOURADO, 1979b); a VII Conferência da Saúde e o compromisso de todos os trabalhadores da saúde com a saúde da população brasileira em amplitude e qualidade (CARVALHO, 1980).

A discussão sobre a Lei 2604/55 que não previa as atribuições diferenciadas entre as diversas categorias da enfermagem e a conseqüente assistência de enfermagem de não qualidade, além da inexistência de empregos para os técnicos de enfermagem que vinham se formando nas escolas de nivel médio (DOURADO, 1980).

A importância da participação da Associação Brasileira de Enfermagem nas questões relativas às políticas de saúde se manifestam em vários editoriais, como mostramos anteriormente e continuam quando fala do seu envolvimento com o PREVSAÚDE, no sentido de colaborar com as ações básicas de saúde para que pudessem beneficiar as camadas mais numerosas da população brasileira.

A ABEn reúne-se a outros setores da vida nacional que tem sua atenção voltadas para o PREVSAÚDE. Colaborará no que lhe compete para que um dia as ações básicas de saúde possam beneficiar camadas mais numerosas da população brasileira. A primeira colaboração é justamente a de divulgar o documento, para que os seus associados possam procurá-lo em suas cidades, estuda-lo com espírito crítico e enviar a sede da associação suas contribuições valiosas (DOURADO, 1981, p. 2).

Percebe-se no conteúdo dos editoriais que Haydée G. Dourado, preocupa-se sempre em conclamar os enfermeiros para que se unam para lutar para criação de melhores serviços de enfermagem que proporcionassem melhor qualidade de assistência (DOURADO, 1981); o CONASP e a possibilidade de melhores condições de atendimento à população (DOURADO, 1983).

Outras editorialistas, como Maria Hélia de Almeida, discutem não só a enfermagem enquanto atividade acadêmica, mas também, a necessidade da integração docente - assistencial como uma forma de crescimento da profissão (ALMEIDA, 1984); também discute a importância de elaborar livros textos de enfermagem para os três niveis de ensino de enfermagem, capacitando melhor os futuros profissionais da enfermagem (CARVALHO, 1985).

Vale ressaltar que até a década de oitenta, a Revista Brasileira de Enfermagem era praticamente o único veículo, aliado aos Congressos Brasileiros de Enfermagem, responsável pela divulgação, orientação dos rumos da enfermagem e da saúde brasileira. Assim, cada idéia, cada chamada de uma temática era lida pelo menos por 1000 associados da ABEn.

No ano de 1986 a Associação Brasileira de Enfermagem completa sessenta anos de existência e várias comemorações são programadas em todo o Brasil para marcar esta data. Uma delas é o primeiro editorial da REBEn, quando a editorialista e Diretora responsável da REBEn, Maria Ivete Ribeiro de Oliveira afirma

$\mathrm{Na}$ programação das atividades desta Associação para o ano em curso, um destaque especial vem sendo conferido à celebração dos seus sessenta anos de vida e história e de sua influência no desenvolvimento da enfermagem brasileira. Este é o temário escolhido para estudo e debate na $47^{\text {a }}$ Semana Brasileira de Enfermagem, bem como para o $37^{\circ}$ Congresso Brasileiro de Enfermagem, a realizar-se no próximo mês de outubro, no Rio de Janeiro. Pretende-se com isso, estimular o interesse de toda comunidade de enfermagem, no pais, inclusive dos estudantes, para uma melhor compreensão das raizes desta Associação, como caminho necessário para uma melhor avaliação de sua trajetória nesses seis lustros (OLIVEIRA, 1986, p. 5).

Dois assuntos permeiam os conteúdos dos editoriais das REBEns de 1986 e 1987 . O primeiro deles é o enfoque

\footnotetext{
${ }^{8}$ Haydée Guanais Dourado ocupou os cargos de coordenadora de Comissão de Legislação, editora e redatora-chefe da REBEn, chegando, inclusive, ao cargo de vice-presidente. Atuou na ABEn de 1939 a 1985 . É o nome mais citado no indice onomástico de Carvalho (1976). Um dos nomes que mais contribuiram para a enfermagem brasileira. Segundo Mancia (2002) a presença de Haydée nas AND da ABEn fazia silenciar um público por 40 minutos, o tempo normal de suas intervenções. Tal deferência se devia, principalmente à luta desta enfermeira para o enquadramento das enfermeiras no nivel técnico-científico de Serviço Público Federal, que se consolidou em 1962.
} 
relativo a nova lei do exercício profissional em 1986, discutindo os vários aspectos inclusos na Lei, em termos críticos e analíticos de seus benefícios para a categoria de enfermagem. Ou seja, a Lei 7.498/86 como não resolutora de todos os problemas da profissão, mas como uma possibilidade de facilitar o trabalho daqueles que se esforçam no sentido do desenvolvimento da assistência do povo brasileiro (PINHEIRO, 1986). "Regozije-se a classe, pois, se a Lei n 7498/86 não vem resolver os problemas da profissão, irá ela certamente facilitar o trabalho daqueles que se esforçam por seu desenvolvimento e por melhor assistência a nosso povo" (PINHEIRO, 1986, p. 5).

No dia 08 de junho de 1987 entrou em vigor no Brasil uma nova legislação do exercicio profissional da enfermagem. (...) Foram quase dez anos de luta da enfermagem brasileira para obtenção da atualização da legislação do exercício profissional. E, uma avaliação mais rigorosa mostra que o resultado deste processo está muito longe do desejado e que uma legislação adequada para a enfermagem ainda é uma necessidade a ser conquistada (LORENZETTI, 1987).

O segundo assunto em destaque no período foi o papel da REBEn enquanto órgão de divulgação da Associação Brasileira de Enfermagem e o seu compromisso social com os profissionais da enfermagem (BURLAMAQUE, 1987), assim como as novas perspectivas para a enfermagem a partir da obtenção de financiamento de parte da produção gráfica da REBEn pelo FINEP (ROSSI, 1987).

\section{TECENDO AS CONSIDERAÇÕES FINAIS}

Ao finalizarmos temporariamente este trabalho, sem a pretensão contudo de concluí-lo, percebemos que os Anais dos Congressos Brasileiros de Enfermagem, e as Revistas Brasileiras de Enfermagem, no periodo compreendido, entre 1977 a 1987, estiveram sempre diretamente ligados a política estabelecida pela ABEn Central. A nosso ver as lideranças da ABEn Central (presidentes) tiveram grande influência e impacto sobre a escolha dos temas bem como dos debatedores, indicando aqueles, com quem tinham maior afinidade. Portanto, os personagens convidados, além do conhecimento que possuiam sobre o tema em questão, em geral procuravam corresponder as solicitações destas lideranças. Com relação a REBEn, a maioria dos editoriais até 1984 tiveram a autoria de Haydée Guanais Dourado, que era editora chefe da revista, contendo então assuntos que permeavam questões da prática profissional, educação em enfermagem e aspectos relativos as politicas de saúde da época.

Ficou evidente a influência da Escola Ana Nery, no Rio de Janeiro, e posteriormente a Escola de Enfermagem da USP, na REBEn e nos CBEns, com docentes nas mesas de temas oficiais dos Congressos. Percebe-se ainda, que, mesmo possuindo outras escolas de peso, nestas duas capitais, como por exemplo a Escola da Enfermagem da UERJ e a Escola de Enfermagem da Escola Paulista de Medicina, estas Escolas apareceram muito pouco. Ressaltase ainda, que as demais Escolas de Enfermagem, nas capitais onde foram realizados os Congressos (Belém, Fortaleza, Brasilia, Manaus, Porto Alegre, Belo Horizonte, Recife e Salvador) demonstraram pouca influência, e uma dependência do eixo São Paulo - Rio de Janeiro.

Podemos perceber que, enfermeiros do campo da prática, pouco tem participado das mesas oficiais dos Congressos, e portanto, pouco tem sido escutado, uma vez que estes aparecem em menor número, sendo marcante a participação de docentes de Escolas Enfermagem de Universidades Federais. Os homens profissionais da Enfermagem, também não marcaram presença nessa época, exceto por aqueles que participaram do próprio movimento PARTICIPAÇÃO. Este aspecto também é percebido nos editoriais da REBEn que são quase que exclusivos dos condutores da ABEn e da REBEn, sendo que em todo o periodo estudado, apenas um editorial, o de 1987 foi escrito por um representante do sexo masculino.

As maiores mudanças observadas na condução dos rumos da $A B E n$ e conseqüentemente das temáticas dos Congressos Brasileiros de Enfermagem e dos autores dos editoriais das REBEns se dão no periodo posterior a 1984 com o movimento PARTICIPAÇÃO, ao assumir a liderança da entidade.

É importante ressaltar que a recuperação que se faz do passado não tem condições de ser totalmente objetiva, como afirmam Borenstein, 1998; Padilha, 1998, considerando que a subjetividade do pesquisador está presente. Neste sentido, o conhecimento do passado se faza luz do presente, construida a partir das evidências escritas ou faladas.

Finalizando, diriamos que o contraponto entre o conteúdo e os personagens que marcaram a produção dos Anais dos Congressos Brasileiros de Enfermagem, e das Revistas Brasileiras de Enfermagem, mostra com clareza que estes são veículos importantes na condução dos rumos da enfermagem brasileira, e neste sentido de fundamental importância enquanto responsabilidade social daqueles que os conduzem.

\section{REFERÊNCIAS BIBLIOGRÁFICAS}

ALMEIDA, M. H. Integração Docente Asistencial e a Enfermagem. Rev. Bras. Enferm., v. 37, n. 2, p. 83-84, ab./ jun. 1984.

BURLAMAQUE, C. S. A Revista Brasileira de Enfermagem e seus compromissos. Rev. Bras. Enferm., v.40 , n. 2 e 3, p. 87, abr./ set., 1987.

CARVALHO, A. C. Associação Brasileira de Enfermagem - 19261976: documentário. Rio de Janeiro: ABEn, 1976.

. Livros texto de Enfermagem. R. Bras. Enferm., v. 38, n. 2, p.113, abr./ jun. 1985

CARVALHO, J. F. A VII Conferência Nacional de Saúde. Rev. Bras. Enferm., v. 33, n.3, p.269-270, jul./ set. 1980.

DIAS, L. P. M.; MONTICELLI, M.; NAZÁRIO, N. O. Editoriais dourados da REBEn. Rev. Bras. Enferm., v. 51, n. 4, p. 547-560, out./dez. 1998.

DOURADO, H. G. Editorial: Comissão de Especialistas do Ensino de Enfermagem. R. Bras. Enferm, v. 32, n.2, p. 137-138, abr./ jun. 1979a.

O novo papel do enfermeiro. Rev. Bras. Enferm, v.32, n. 4, p. 357-358, out./ dez, 1979b. 
Um contraponto entre os personagens...

Programa Nacional de Serviços Básicos de Saúde (PREVSAÚDE). Rev. Bras. Enferm, v.34 , n.1, p. 1-2, jan./mar. 1981.

Fortalecendo a profissão. Rev. Bras. Enferm., v. 35, n.1, p. 2, 1982.

A enfermagem e a assistência à saúde. Rev. Bras. Enferm., v.33,p. 391, out./ dez. 1980.

O CONASP (Conselho Consultivo de Administração de Saúde Previdenciária). Rev. Bras. Enferm, v.36 , n.2, p. 121122, abr./ jun. 1983.

LOBO, R. H. Aera nova. Annaes de Enfermagem, v. 1, n. 1, p. 5, maio 1932

LORENZETTI, J. Legislação adequada para a enfermagem: uma necessidade a ser conquistada. R. Bras. Enferm., v. 40, n.4, out./ dez. 1987.

MANCIA, J. A ABEn-RS e as enfermeiras assistenciais - uma análise reflexiva. 2002. 93f. Dissertação (Mestrado em Enfermagem) - Programa de Pós-Graduação em Enfermagem da UFSC, Florianópolis.

OLIVEIRA, M.I.R. Associação Brasileira de Enfermagem (ABEn) - 60 anos e a enfermagem brasileira. Rev. Bras. Enf., v. 39, n.1, jan./ mar. 1986.

PEREIRA, Á. Contextualizando a ABEn no período 80/84. Florianópolis, 1995. (Digitado).

PINHEIRO, M., R., S. ALein. 7.498/86. Rev. Bras. Enferm., v. 39, n. 2 e3, p.5, abr./set. 1986.

ROSSI, M.J.S. Novas perspectivas para a enfermagem. Rev. Bras. Enferm., v. 40, n.1, jan./ mar. 1987. 